\title{
DEGRADED PET FOR THE REMOVAL OF METAL IONS FROM AQUEOUS SOLUTION
}

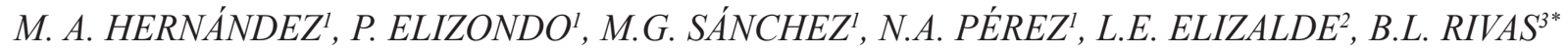 \\ ${ }^{1}$ Universidad Autónoma de Nuevo León, UANL, Facultad de Ciencias Químicas, Av. Universidad S/N Ciudad Universitaria San Nicolás de los Garza Nuevo \\ León CP 66451 México. \\ ${ }^{2}$ Centro de Investigación en Química Aplicada. Blvd. Enrique Reyna H. No.140, C.P. 25100. Saltillo, Coahuila, México. \\ ${ }^{3}$ Polymer Department, Faculty of Chemistry, University of Concepción, Casilla 160-C, Concepción 4070371, Chile.
}

\begin{abstract}
Poly(ethylene terephthalate) waste was degraded by glycolysis in order to obtain low molecular weight molecules for the batch removal of Cd(II), $\mathrm{Cr}(\mathrm{III})$, $\mathrm{Cu}(\mathrm{II}), \mathrm{Ni}(\mathrm{II})$, and $\mathrm{Pb}$ (II) from aqueous solution. The degradation product was characterized by IR, $\mathrm{H}^{1} \mathrm{NMR}$, DSC, and GPC, being identified as bis(2-hydroxy ethyl) terephthalate (BHET). The results show that metal absorption follows the order $\mathrm{Pb}$ (II) $>\mathrm{Cd}(\mathrm{II})>\mathrm{Ni}(\mathrm{II})>\mathrm{Cu}$ (II) $>\mathrm{Cr}$ (III). Degraded $\mathrm{PET}$ presented an affinity to remove over $75 \%$ of lead in solution at $\mathrm{pH} 4$ and 5 and cadmium over $70 \%$ at $\mathrm{pH}$. IR spectroscopy and DSC evidenced the presence of metal ions in the structure of the material.
\end{abstract}

Keywords: adsorption, metal ions, PET degradation, removal.

\section{INTRODUCTION}

Pollution caused by the presence of heavy metal ions is of great importance because some of these species have high toxicity at low concentrations. Toxic metals as lead, chromium, copper, nickel, cadmium, and zinc are released into the water mainly through industrial activities ${ }^{1}$.

Different materials such as homopolymers and modified polymers ${ }^{2}$ including polypropylene ${ }^{3}$, polyacrylic acid ${ }^{4}$, polyacrylamide ${ }^{5}$, polyurethane ${ }^{6}$, polyethylene terephthalate 7,8 among others, have been studied to reduce the amount of heavy metals in aqueous solution.

PET, principally as fibers, has been used as a stripping agent for metal ions. It has also been grafted with different molecules like itaconic acid/acrylamide ${ }^{7}$, acrylic acid ${ }^{9}$, methacrylic acid $^{10}$, acrylic acid/acrylamide ${ }^{11}$, acrylonitrile ${ }^{12}$, hydroxylamine and vinyl pyridine $e^{13}$ in order to increase its adsorption capacity towards metal ions. Nevertheless, if virgin PET is used for this purpose new waste is generated and does not contribute to solve the global plastic accumulation problem.

In view of the fact that high amounts of PET bottles become waste, different recycling and chemical degrading processes have been studied in order to control this situation. Chemical degradation of PET produces low molecular weight compounds with functional groups taken from the nucleophilic agent used in the chemical process, for example, hydroxyl group in glycolysis or amine group in aminolysis ${ }^{14}$. These degradation products have been used as precursors of new products such as fatty amide derivate in textile processes ${ }^{15}$, unsaturated polyester resins ${ }^{16}$, epoxy resin hardeners ${ }^{17}$, and polyurethanes ${ }^{18}$. Due to the nature of the generated functional groups, products of PET chemical recycling can be considered as an alternative for the removal of metal ions from water and consequently help resolve many problems caused by plasticaccumulation ${ }^{19,20}$.

The aim of this manuscript is to study the removal of $\mathrm{Cd}(\mathrm{II}), \mathrm{Cr}(\mathrm{III}), \mathrm{Cu}(\mathrm{II})$, $\mathrm{Ni}(\mathrm{II})$, and $\mathrm{Pb}$ (II) from aqueous solution, at various $\mathrm{pH}$ values and metal ion concentration using water-insoluble products of PET glycolysis.

\section{Materials and equipment}

Zinc acetate, copper, nickel, cadmium, chromium and lead nitrates, ethyleneglycol, nitric acid and $\mathrm{NaOH}$ were purchased from Sigma Aldrich and used without further purification. Bottle grade PET was rinsed with detergent solution at room temperature for $1 \mathrm{~h}$ and then washed with water. Washed PET was filtered and dried at $70^{\circ} \mathrm{C}$ for $24 \mathrm{~h}$.

Infrared analysis was performed using a Magna Nicolet IR-550 spectrometer coupled with ATR. The Nuclear Magnetic Resonance spectrum of the samples was obtained using a Bruker Advance III 500 Plus spectrometer, operating at $500 \mathrm{MHz}$ in deutered chloroform. A Perkin Elmer Sapphire Differential Scanning Calorimeter was used to determine the thermal behavior of the samples at a heating rate of $20^{\circ} \mathrm{C} / \mathrm{min}$ from 10 to $350{ }^{\circ} \mathrm{C}$ under nitrogen atmosphere. The molecular weight was determined through Gel Permeation Chromatography (GPC) in an Agilent HP 1100 chromatograph, using THF as mobile phase; PET and degradation product samples were dissolved in a mixture of 1,1,1,3,3,3-hexafluoroisopropanol and $\mathrm{CHCl}_{3}$ The not retained metal ion concentration was determined using a Unicam Solaar5 MS Series Absorption Atomic Spectrophotometer.

\section{EXPERIMENTAL}

To carry out the degradation reaction, $5 \mathrm{~g}$ of PET were mixed with $27 \mathrm{~mL}$ $(30 \mathrm{~g})$ of ethyleneglycol and $250 \mathrm{mg}$ of zinc acetate as a catalyst. The reaction mixture was heated at $180^{\circ} \mathrm{C}$, under magnetic stirring for $6 \mathrm{~h}$, then $50 \mathrm{~mL}$ of distilled water were added and the mixture was left to cool down in an ice bath to precipitate water-insoluble product. The product was filtered, dried and then characterized by IR, ${ }^{1} \mathrm{H}-\mathrm{NMR}$, DSC, and GPC. The degradation reaction is presented in Scheme 1.

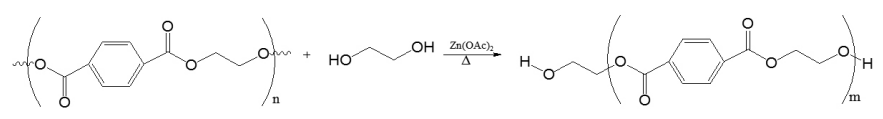

Scheme 1. Chemical degradation of PET using ethyleneglycol.

Removal of metal ions was investigated under batch equilibrium conditions. To determine the effect of $\mathrm{pH}, 20 \mathrm{~mL}$ of $25 \mathrm{mg} / \mathrm{L}$ aqueous solution of the different metal ions were treated with $50 \mathrm{mg}$ of degraded PET at different $\mathrm{pH}$ values (3-7) adjusted with dilute $\mathrm{HNO}_{3}$ or $\mathrm{NaOH}$. To analyze the effect of the initial concentration at $\mathrm{pH} 5,20 \mathrm{~mL}$ of the metal ion solutions at different concentrations $(5-100 \mathrm{mg} / \mathrm{L})$ were placed in a tube with $50 \mathrm{mg}$ of degraded PET. All the experiments were shaken at $140 \mathrm{rpm}$ at $25{ }^{\circ} \mathrm{C}$ during $2 \mathrm{~h}$. The solutions were filtered in order to separate degraded PET from the solution and the metal ion concentration in the aqueous phase was determined using AAS. The metal uptake ratio was calculated according to Eq. 1:

$$
\% R=\frac{C_{i}-C_{l}}{C_{i}} x 100 \quad \text { Equation (1) }
$$

Where $\% \mathrm{R}$ is the percentage of the uptake metal ion, $\mathrm{C}_{\mathrm{i}}$ is the initial concentration of the metal ion solution and $\mathrm{C}_{1}$ is the residual concentration of metal ions in solution after a certain contact time with degraded PET. After retention studies, degraded PET (loaded with lead and virgin) was characterized in order to determine the possible interactions between metal ions and functional groups from the degraded polymer.

\section{RESULTS AND DISCUSSION}

\section{PET degradation}

PET was degraded using zinc acetate as catalyst, obtaining a white 
precipitate in $92 \%$ yield, which is higher than yields reported in other manuscripts when acetic acid, lithium hydroxide, sodium sulfate, and potassium sulfate are used as catalysts $(54-60 \%)^{21}$. Moreover, the excess of ethyleneglycol in the reaction mixture allows a complete degradation after $3 \mathrm{~h}$ of reaction, as shown in Figure 1, which is faster compared to a lower molar ratio studied previously ${ }^{15,22-23}$. The maximum yield was obtained after 4 hours.

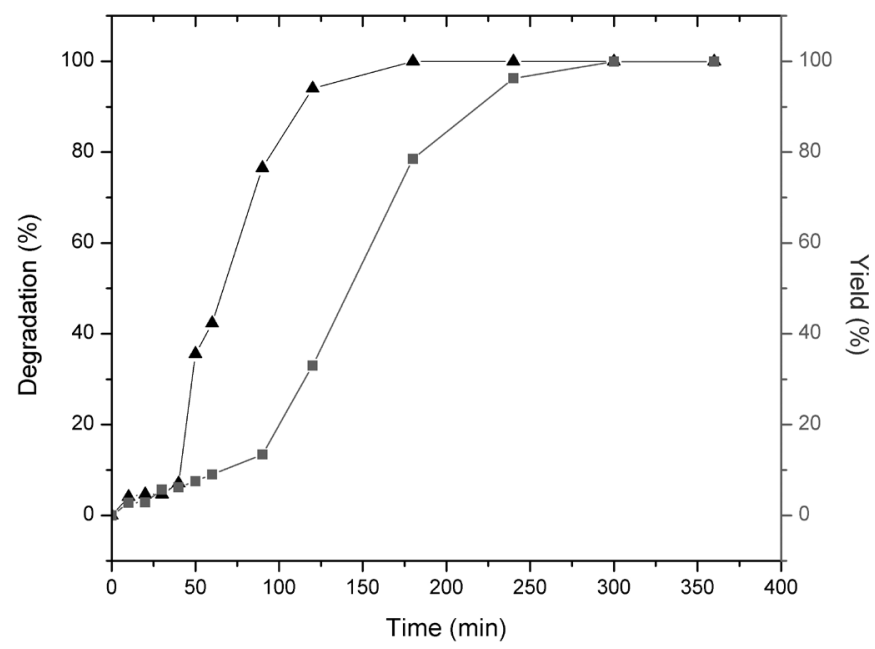

Figure 1. Effect of time on PET by ethylene glycol ( $\mathbf{\Delta})$ and on the yield $(\mathbf{a})$

FTIR spectrum of degraded PET presents principally the absorption signals corresponding to the $\mathrm{OH}$ stretching tension bond at $3439 \mathrm{~cm}^{-1}$, the $\mathrm{C}=\mathrm{O}$ stretching bond of the ester group at $1714 \mathrm{~cm}^{-1}$ and the $\mathrm{C}-\mathrm{OH}$ peak at $1126 \mathrm{~cm}^{-}$ ${ }^{1}$. The $\mathrm{H}^{1} \mathrm{NMR}$ spectrum shows the signals of the expected functional groups. The corresponding signals to the methylene group located next to the hydroxyl and ester group were found at $\mathrm{d}=3.4$ and $3.7 \mathrm{ppm}$, the signal that corresponds to the proton of the hydroxyl group was found at $\mathrm{d}=4.5 \mathrm{ppm}$ and the signals that represent the protons of the aromatic ring can be seen at $\mathrm{d}=8.2 \mathrm{ppm}$.

The DSC thermogram of the degradation product shows an endothermic process at $106{ }^{\circ} \mathrm{C}$ which is attributed to its melting point. At $260{ }^{\circ} \mathrm{C}$ there is no sign of any transition that could correspond to the original polymer's melting point, which proves a complete degradation.

The molecular weight determined by GPC was $383 \mathrm{~g} / \mathrm{mol}$ and is thought to be bis(2-hydroxy ethyl) terephthalate (BHET) dimer. Conjointly, the determined molecular weight, the endothermic process that represents the sample's melting temperature in the thermogram and the absorption signals in the IR and $\mathrm{H}^{1} \mathrm{NMR}$ spectrum are attributed to the formation of BHET, as it was proposed in Scheme 1, when $\mathrm{m}=1.5-2$.

\section{Removal of metal ions}

Effect of $\mathrm{pH}$ values in metal ions removal from an aqueous solution by degraded PET is shown in Figure 2. At lower $\mathrm{pH}$ values due to high concentration of hydronium ions $\left(\mathrm{H}_{3} \mathrm{O}^{+}\right)$there is a competition between these and metal ions $\left(\mathrm{M}^{\mathrm{n}+}\right)$ for the functional groups in degraded PET (hydroxyl and ester groups). In these conditions, the heteroatoms (X) with lone pairs are preferentially bonded with protons, which decrease the degraded polymer's removal capacity towards metal ions. When solution $\mathrm{pH}$ increased, metal uptake was enhanced as a result of the decreasing proton concentration which made the heteroatoms more available to interact with metal ions, increasing its retention onto degraded PET.

The variation of metal ion retention when modifying $\mathrm{pH}$ values has a similar effect on $\mathrm{Pb}$ (II) and $\mathrm{Cd}(\mathrm{II})$; the higher metal ion uptake for $\mathrm{Pb}$ (II) was achieved at $\mathrm{pH} \mathrm{4-5}$ and $\mathrm{Cd}(\mathrm{II})$ at $\mathrm{pH}$ 6. The results show lower removal concentrations for $\mathrm{Ni}(\mathrm{II}), \mathrm{Cu}(\mathrm{II})$, and $\mathrm{Cr}(\mathrm{III})$, since these ions are easily complexed with hydroxyl ions $\left(\mathrm{OH}^{-}\right)$this species decrease their retention onto degraded PET. Additionally, charge and size of each formed species play an important role due to the competence for heteroatoms between all the metal species in solution ${ }^{2,5}$

Degraded PET preferentially removes $\mathrm{Pb}(\mathrm{II})$ and $\mathrm{Cd}(\mathrm{II})$ showing the following order of retention at $\mathrm{pH} 4$ and $5: \mathrm{Pb}$ (II) $>\mathrm{Cd}$ (II) $>\mathrm{Ni}$ (II) $>\mathrm{Cu}$ (II) $>\mathrm{Cr}$ (I II), these results coincide with other reports, attributing this order to factors like complexation abilities, which can be explained by hard and soft acids and bases
(HASB) theory ${ }^{24-26}$, trends of hydrated radius, polarizability, and electronic configuration $^{27-29}$.

Figure 2. Retention of metal ions by degraded PET at different $\mathrm{pH}$. (25 $\left.\mathrm{mg} / \mathrm{L}, 25^{\circ} \mathrm{C}\right)$

The effect of initial concentration at $\mathrm{pH} 5$ is shown in Figure 3. There is a greater retention at lower initial concentrations of each studied metal, this retention decreases as the metal concentration increases due to saturation of the available functional groups in the degraded polymer.

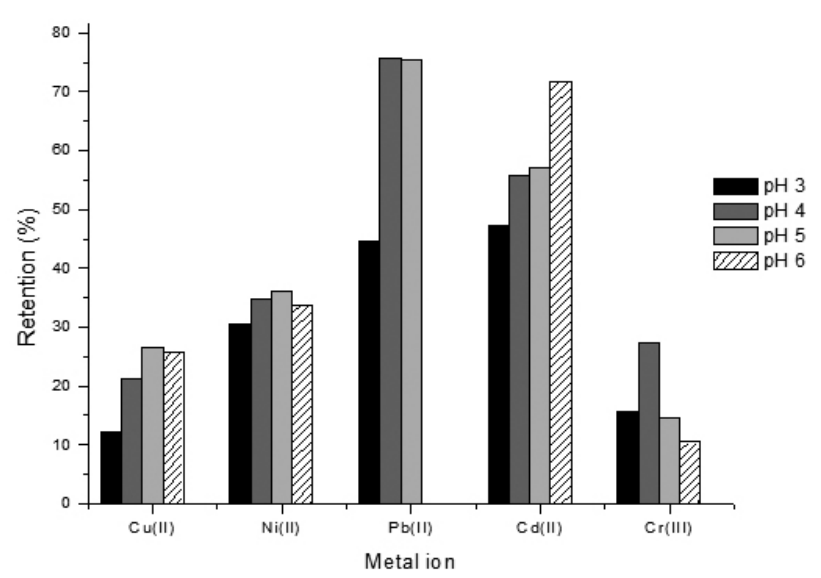

Figure 3. Retention of metal ions by degraded PET at different initial concentrations.

$\left(\mathrm{pH} 5,25^{\circ} \mathrm{C}\right)$.

The retention values obtained are comparable with other studies when PET was used to remove metal ions like $\mathrm{Cu}(\mathrm{II}), \mathrm{Co}(\mathrm{II}), \mathrm{Fe}(\mathrm{II}), \mathrm{Pb}$ (II), and $\mathrm{Ni}(\mathrm{II})$ among others. The PET fibers without modification, remove between 22 and $46 \%$ and when PET fibers are grafted the retention increases significantly (35$95 \%$ ) at similar conditions that the experiments carried out in this study. The process of functionalization sometimes requires Soxhlet extraction, use of dissolvent, radical initiator, or vacuum. Meanwhile, the chemical degradation of PET allows by precipitation with water to obtain an insoluble product for retention experiments ${ }^{7-13,30}$.

FTIR spectra of degraded PET and degraded PET-Pb(II) are shown in Figure 4. The comparison of both IR spectra reveal the interaction between the metal ion and degraded PET, which was evidenced by a shift in the positions of the absorption peaks, principally de disappearing of O-H signal at $3439 \mathrm{~cm}^{-1}$, a splitting of the $\mathrm{C}-\mathrm{OH}$ signal at $1265 \mathrm{~cm}^{-1}$, and the change of the ester group $\mathrm{C}=\mathrm{O}$ peak's intensity at $1714 \mathrm{~cm}^{-1}$ as a result of the coordinate bond between oxygen and metal atoms ${ }^{2}$. In scheme 2 the proposed interaction between degraded PET and metal ions through hydroxyl groups is shown.

Degraded PET's DSC thermogram before and after contact with lead is presented in Figure 6, where an endothermic absorption is shown at approximately in $106{ }^{\circ} \mathrm{C}$. There was a decrease in the intensity through the packing of the molecules, therefore the energy required to melt the material is lower.

\section{CONCLUSIONS}

BHET obtained from PET glycolysis removes preferentially $\mathrm{Pb}(\mathrm{II})$ and $\mathrm{Cd}$ (II) from aqueous solution. The order of metal ion retention at $\mathrm{pH} 4$ and 5 was $\mathrm{Pb}(\mathrm{II})>\mathrm{Cd}(\mathrm{II})>\mathrm{Ni}(\mathrm{II})>\mathrm{Cu}(\mathrm{II})>\mathrm{Cr}(\mathrm{III})$. These results are attributed to complexation abilities, charge and size of each formed species. The metal speciation of $\mathrm{Ni}(\mathrm{II}), \mathrm{Cu}(\mathrm{II})$, and $\mathrm{Cr}(\mathrm{III})$ decrease the uptake of these metals. The presence of metal ions in BHET's structure was evidenced principally by FTIR spectroscopy, through the observed shifting of characteristic signals of functional groups. 

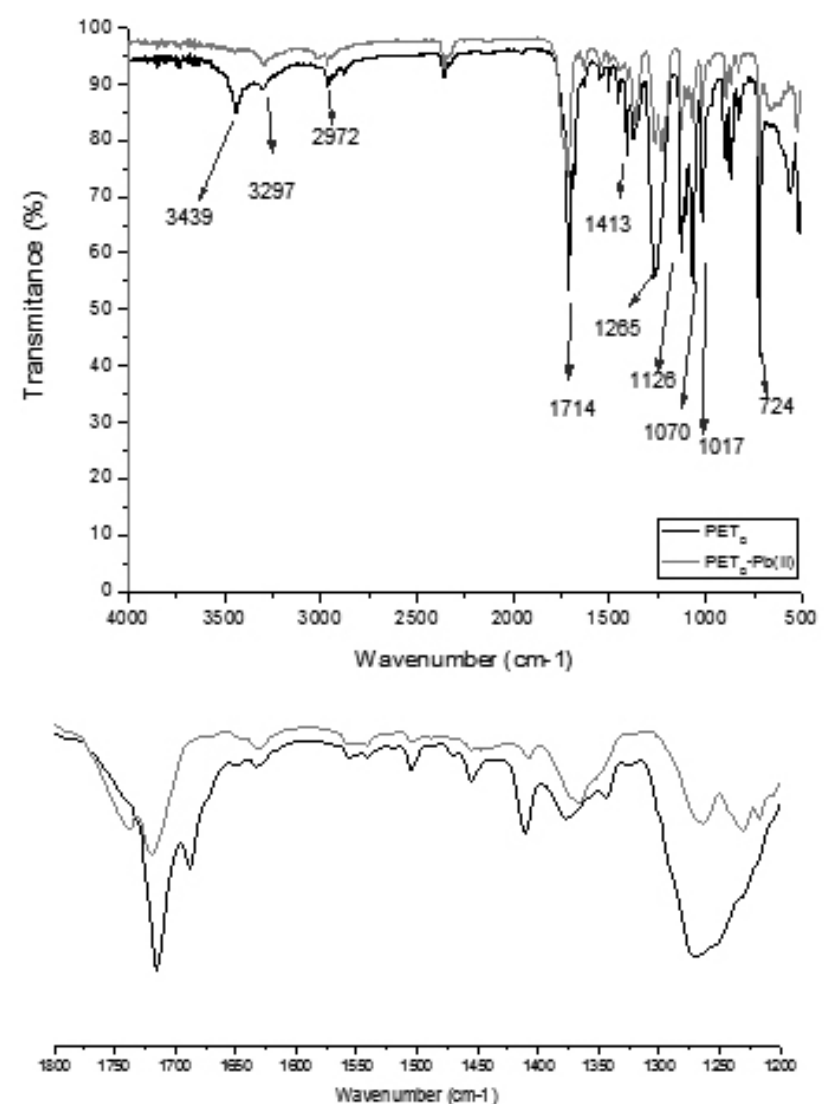

Figure 4. IR spectra of degraded PET before and after contact with $\mathrm{Pb}(\mathrm{II})$.

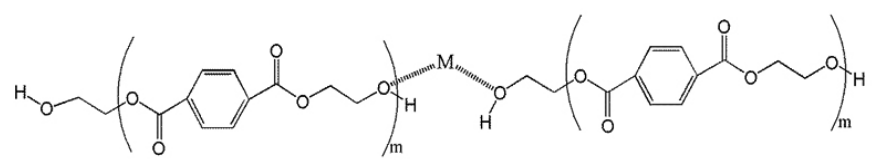

Scheme 2. Proposed metal ion interaction between degraded PET and metal ions.

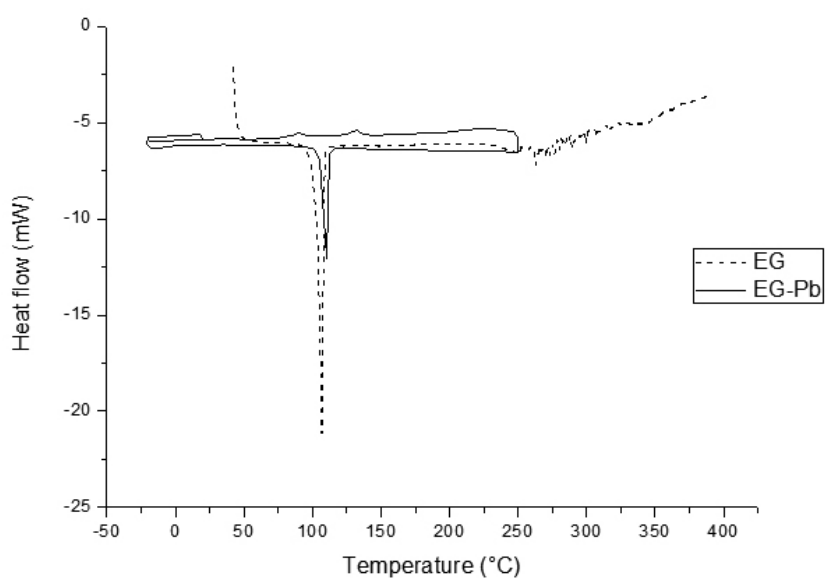

Figure 5. DSC thermogram of degraded PET before and after contact with $\mathrm{Pb}(\mathrm{II})$.

$\left(10^{\circ} \mathrm{C} / \mathrm{min}, \mathrm{N}_{2}\right)$

\section{ACKNOWLEDGMENTS}

The authors would like to thank CONACyT (Scholarship 336888), CIQA, PIA (Grant Anillo ACT 130), FONDECYT (Grant No 1150510), REDOC (MINEDUC Project UCO1202 at U. de Concepción), PAICyT (Project CN646-
11) and the Facultad de Ciencias Químicas, UANL for funding this project.

\section{REFERENCES}

[1] Jimenez, B.La contaminación ambiental en México.Limusa: México, 2002

[2] Rivas, B.L., Maturana, H.A., Pereira, E., Angew. Makromol. Chem. 220, 61 (1994)

[3] Perez, L., Rivas, B., Coiai, S., Passaglia, E., Augier, S., Ciardelli, F. J. Appl. Polym. Sci. 113, 290 (2009).

[4] Bejarano, L., Rojas, B., Prin, J.Mohsin, M., García, A., Mostue, M., Rojas, L., Ramírez, M., Katime, I. Rev. Iberoam. Pol. 9,307 (2008).

[5] Rivas, B., Pooley, S., Maturana, H., Villegas, S. Macromol. Chem. Phys. 202, 443 (2001)

[6] Yang, X., Wang, J., Cheng, C. Chin. Chem. Lett. 24, 383 (2013).

[7] Coskun, R., Soykan, C., Saçak, M. Reac. Funct. Polym. 66, 599 (2006).

[8] Meng, Y., Wang, J N., Xu, L. Li, A. Chin. Chem. Lett. 23, 496 (2012).

[9] Karakisla, M. J. Appl. Polym. Sci. 87, 1216 (2003).

[10] Coskun, R., Yigitoglu, M., Sacak, M. J. Appl. Polym. Sci. 75, 766 (2000).

[11] Ahmad Panahi, H., Abdouss, M., Ghiabi, F. Moniri, E., Mousavi Shoushtari, A. J. Appl. Polym. Sci. 124, 5236 (2012).

[12] Coskun, R., Soykan, C. J. Appl. Polym. Sci. 112, 1798 (2009).

[13] Yigitoglu, M., Arslan, M. J. Hazard. Mater. 166, 435 (2009).

[14] Shukla, S. R., Kulkarni, K. S. J. Appl. Polym. Sci. 85, 1765 (2002).

[15] Shukla, S. R., Harad, A. M, Jawale, L. S. Waste Manage. 28, 51 (2008).

[16] Abdelaal, M. Y., Sobahi, T. R., Makki, M. S. I. Constr. Build. Mater. 25, 3276 (2011).

[17] Spychag, T., Pilawka, R., Spychaj, S., Bartkowiak, A. Ind. Eng. Chem. Res. 43, 862 (2004).

[18] Shamsi, R., Abdouss, M., Sadeghi, G, Taromi, F. Polym. Int. 58, 22 (2009).

[19] Awaja, F., Pavel, D. Eur. Polym. J. 41, 1453 (2005).

[20]Li, M-J., Huang, Y-H., Ju, A-Q., Yu, T-S., Ge, M-Q. Chin. Chem. Lett. 25, $1550(2014)$

[21] Shukla, S. R., Harad, A. M. J. Appl. Polym. Sci. 97, 513 (2005).

[22] Pticek, A., Fijacko, A., Hrnjak-Murgic, Z. Chem. Biochem.. Eng. Q. 27, 63 (2013).

[23] Chen, C. J. Appl. Polym. Sci. 87, 2004 (2003).

[24] Nieboer, E., Richardson, D. Environ. Pollut. B 1, 3 (1980).

[25] Puranik, P., Paknikar, K. Biotechnol. Progr. 15, 228 (1999).

[26] Badruddoza, A. Z. M., Shawon, Z. B. Z Tay, W. J. D., Hidajat, K., Uddin, M. S. Carbohyd. Polym. 91, 322 (2013).

[27]Rivas, B., Pooley, A, Maureira, A. J. Appl. Polym. Sci. 92, 2955 (2004).

[28]Fu, W., Wang, Q. J. Environ. Manag. 92, 407 (2011).

[29] Coskun, R., Soykan, C., Saçak, M. J. Appl. Polym. Sci. 112, 1798 (2009).

[30] Yigitoglu, M., Ersoz, M., Coskun, R., Sanli, O., Unal, H.L. J. Appl. Polym. Sci. 68, 1935 (1998). 